\title{
ATTENTION FUNCTION STRUCTURE OF OLDER AND YOUNGER ADULT DRIVERS
}

\author{
Stephanie Tuttle, Nicholas Cassavaugh, and Richard W. Backs \\ Central Michigan University \\ Mount Pleasant, MI USA

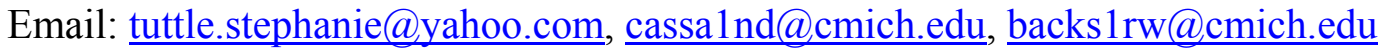

\begin{abstract}
Summary: Groups of younger $(n=49, M$ age $=21.7$ years) and older $(n=52, M$ age $=73.0$ years) adults performed computer-based cognitive tests and simulated driving. Results from the cognitive tests were submitted to Principal Components Analysis (PCA) and 6 components were extracted that explained more than $77 \%$ of the variance. The components were labeled speed, divided, sustained, executive, selective/inhibition, and visual search in descending order of amount of variance explained. The component scores were used to predict simulated driving performance. Hierarchical step-wise regressions were computed with driving performance as the criterion, and age group (forced) and the component scores (step-wise) as predictors. Results showed that the speed and divided components were more likely to explain additional driving performance variance beyond age group than the other components.
\end{abstract}

\section{INTRODUCTION}

Assessment of driving ability is likely to be necessary in the later years of the life span as the population of the U.S. ages as a result of the baby boom generation reaching retirement age (Eby, Molnar, \& Kartje, 2009). Aging affects driving in several ways, which can be inferred by the increase in the number of accidents per mile driven for older drivers (U.S. DOT, 2005). The goal of the present study was to develop a comprehensive attention assessment test battery that can be used for any age group but that was sensitive to the areas of concern for the aging driver as well as for other demographic groups with attention dysfunction. The assessment focused on the functional profile of five functions of attention (selective, visual search/scanning, divided, switching, and sustained) using a computer battery modeled upon the ASAP (Assessment Software for Attention Profiles, Washburn \& Putney, 1997). The present study explored the attention functions separately for young and old age groups in an effort to identify the relation and consistency between the factor solutions for the two groups. The purpose of the study was to test whether a single component structure could be used for both the young and old adults or if separate component structures are needed. This study also explored the relationship of the factor scores to measures of simulated driving performance.

\section{METHOD}

\section{Participants}

There were two groups of participants to assess the consistency of the component structure of attention functions in young and old adults. The younger group consisted of participants who were Central Michigan University students 18-34 years-of-age solicited from the Department of 
Psychology subject pool and compensated with course credit. The mean age of the young group was 21.7 years and there were 31 females $(63.3 \%)$ and 18 males $(36.7 \%), 73.5 \%$ (36) of whom were Caucasian/White, 4.1\% (2) were American Indian, 8.2\% (4) were Asian/Pacific Islander, $10.2 \%$ (5) were African American, and 4.1\% (2) were other ethnicities. The older group was 6087 years-of-age who were recruited throughout the community from a database of older adults that had previously participated in research and from an advertisement placed in the local Commission on Aging senior newspaper. The older group was compensated $\$ 15.00$ per hour. The mean age of the older group was 73.0 years and there were 34 females $(66.0 \%)$ and 18 males (34.0\%), 98.1\% (52) of whom were Caucasian/White and 1.9\% (1) were other ethnicities.

\section{Procedure}

Each participant was seen individually for one data collection session. After giving informed consent, participants completed a demographic questionnaire, a driving knowledge questionnaire (Secretary of State, 2004), a driving behavior survey (Barkley et. al., 2002), an older driver questionnaire that may indicate problem areas with an older driver adapted from Eby, Molnar, and Shope (2000), a driving history survey (Barkley et. al., 2002), and a motion sickness history questionnaire (Golding, 2006). Participants were assessed cognitively with the Mini Mental State Exam (MMSE, Folstein, Folstein, \& McHugh, 1975). Participants' visual acuity and peripheral vision was tested using the Keystone View DVS II Driver vision tester. Participants then completed a computer task battery for the five functions of attention: visual search/scanning, selective, divided, switching, and sustained. Tasks in the battery were a two-choice reaction time task (RT-2), a two color version of the Stroop task (Stroop, 1935), the attention network task (ANT, Fan et al., 2002), a visual search task (Neisser, 1963), Trail Making Test Parts A and B (Reitan, 1958), the Anti-cue and Pro-cue tasks (Hallett, 1978), a continuous performance task (CPT), and a dual task of single axis compensatory tracking and two-choice reaction time task. Finally, participants completed a brief driving simulation course. The length of the procedure for each participant was approximately $120 \mathrm{~min}$.

\section{Driving Simulation}

The virtual driving world was created using Hyperdrive simulation programming software (version 1.9.25) presented to the participant using a DriveSafety desktop driving simulator. Participants were seated on an automobile seat mounted on a platform with a desk placed in front of the seat that had a force-feedback steering wheel and pedals attached. A 20 in. LCD flat panel display included the driving scene, a digital speedometer, and a rear view display. Participants were presented a scenario to assess their driving performance on a subset of the situations relevant to older drivers identified by Korner-Bitensky et al. (2005). The scenario was a carfollowing task through highway, suburban, urban, residential, and industrial sections and included merging, speed decreases and increases, switching lanes, stop signs, stop lights, left and right turns, and opposing traffic. Participants were instructed to follow all traffic laws and to follow the lead vehicle, which was programmed to wait for the participant if $\mathrm{s} /$ he lagged a certain distance. Driving performance measures were divided into driving event type: continuous, stopturn, stop, merge, slow, and multi-merge. If participants experienced motion discomfort symptoms during the simulated driving they stopped participating, which resulted in a different number of completed events for both age groups. Driving performance data were collected at 60 
$\mathrm{Hz}$ throughout the scenario. The duration of the driving simulation was approximately 15 min. depending on driving speed.

\section{RESULTS}

The young and old groups were composed of cognitively healthy individuals. The old group $(M=33.02, S D=2.33)$ had lower MMSE scores than the young group $(M=33.94, S D=1.94)$, although all scores were at or above the cutoff score of $23, t(100)=2.11, p=.033$. The majority of both age groups had acceptable visual acuity (at least 20/40) according to the State of Michigan regulations for drivers.

Principal Component Analysis (PCA) was performed for the young and old groups separately and combined to find an overall component structure of the attention task variables. A number of exploratory analyses were done to determine the optimum number of variables and components to use that would explain the variance in the most logical way, while attempting to maximize the subject to variable ratio. Variables were removed that were found to contribute minimal variance to the component structure in preliminary analyses.

The final analysis resulted in the inclusion of 21 out of the 38 possible variables and 6 components. PCA with varimax rotation was done for the $z$-scores (computed separately for younger and older groups) of the RT's from the RT-2 task, visual search feature and pop-out tasks, Anti-cue and Pro-cue tasks, Stroop congruent and incongruent task trial types, CPT, the dual-task tracking RMSE and RT and accuracy, the alerting, orienting, and executive scores from the ANT task, as well as the total time for Trail Making Test Parts A and B. Case-wise exclusion was done yielding a total sample of 93 participants: 44 younger and 49 older participants.

\section{Table 1. Total Variance Explained from PCA}

\begin{tabular}{|c|c|c|c|c|c|c|}
\hline \multirow[b]{3}{*}{ Component } & \multicolumn{3}{|c|}{ Extraction Sums of Squared Loadings } & \multicolumn{3}{|c|}{ Rotated Sums of Squared Loadings } \\
\hline & Eigen & $\%$ of & Cumulative & Eigen & $\%$ of & Cumulative \\
\hline & Value & Variance & $\%$ & Value & Variance & $\%$ \\
\hline 1 (Speed) & 8.16 & 38.87 & 38.87 & 5.53 & 26.36 & 26.36 \\
\hline 2 (Divided) & 2.32 & 11.07 & 49.94 & 3.43 & 16.35 & 42.70 \\
\hline 3 (Sustained) & 1.88 & 8.697 & 58.91 & 2.32 & 11.03 & 53.74 \\
\hline 4 (Executive) & 1.50 & 7.16 & 66.07 & 1.80 & 8.55 & 62.29 \\
\hline 5 (Selective/Inhibition) & 1.40 & 6.66 & 72.72 & 1.59 & 7.55 & 69.83 \\
\hline 6 (Visual Search) & .916 & 4.36 & 77.09 & 1.52 & 7.26 & 77.09 \\
\hline
\end{tabular}

PCA solutions for the two age groups were found to be similar with two exceptions: 1) the younger group had more of the dual-task variance load with Component 1 (the Speed Component) than the older group; whereas the older group had less variance load on the Trails and Stroop tasks than the younger group. The combined solution used in the current study is presented below. Table 1 contains the amount of variance explained by the 6 components extracted through the PCA, before and after varimax rotation. Table 2 contains the rotated component matrix from the PCA analysis with varimax rotation. The components were named Speed, Divided, Sustained, Executive, Selective/Inhibition, and Visual Search based upon the pattern of component loadings. 
Table 2. Rotated PCA Component Matrix

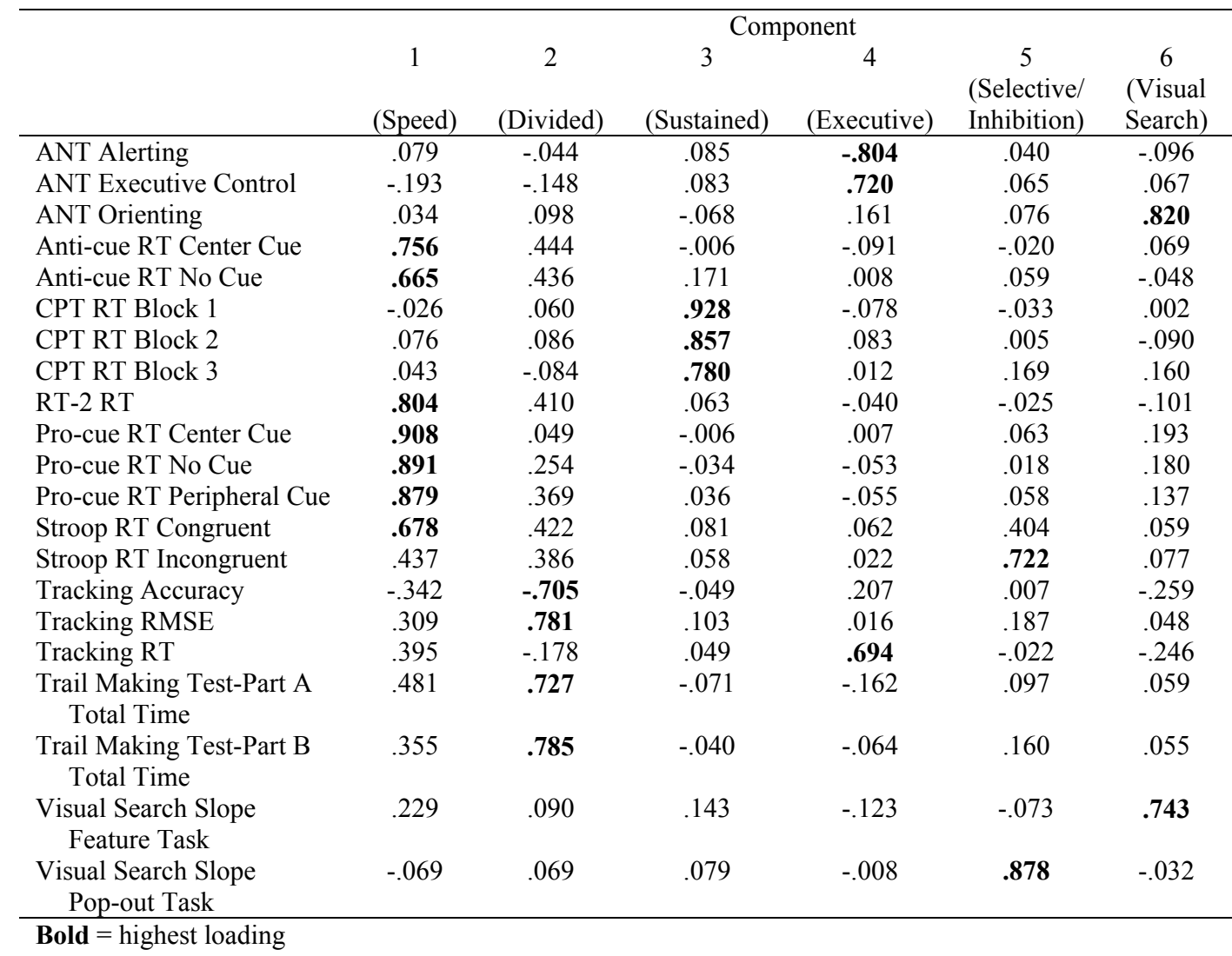

More younger participants $(95.7 \%)$ drove to the end of the scenario than older participants $(59.6 \%)$. Reasons why participants were unable to complete the scenario included motion discomfort, equipment failure, and other various individual reasons such as failing to get the hang of driving with gaming controls. Ending time in seconds was used to determine the how long each participant drove. The younger group had a mean of $930.72 \mathrm{~s}(S D=140.09)$, with times ranging from 113.17 to $1177.12 \mathrm{~s}$; whereas the older group had a mean of $852.84 \mathrm{~s}(S D=339.35)$, with times ranging from 39.70 to $1454.20 \mathrm{~s}$. The older participants drove more slowly and over a shorter distance compared to the younger participants.

Only simulated driving performance data from the first few events in the scenario were analyzed to maximize the number of older participants. The events that we used were a straight on a sixlane divided highway, the merge off of the highway, and a suburban straight in a 5-lane with center turn roadway. The two straight sections differed in the speed limit, $65 \mathrm{mph}$ for the highway section and $35 \mathrm{mph}$ for the suburban section. For each event we examined the standard deviation ( $\mathrm{SD}$ in $\mathrm{m}$ ) of the following distance from the lead vehicle, the root mean squared error (RMSE in $\mathrm{m}$ ) of lateral position from the center of the lane, mean velocity (in $\mathrm{km} / \mathrm{h}$ ), and time to complete the event (in s). For each driving performance measure we conducted a hierarchical step-wise regression. Age group was entered in the first step, and then the six component scores were step-wise entered using $p<.05$ to enter and $p<.10$ to remove. Table 3 presents the results for the significant driving performance measures. 
Table 3. Significant Results of Regression Analyses of Driving Performance

\begin{tabular}{|c|c|c|c|c|c|c|c|c|}
\hline $\begin{array}{l}\text { Driving Performance } \\
\text { Measure }\end{array}$ & $\begin{array}{l}\text { Selection } \\
\text { Level }\end{array}$ & $\begin{array}{l}\text { Predictors } \\
\text { Entered }\end{array}$ & $\mathrm{R}^{2}$ & Adj- $R^{2}$ & $\Delta \mathrm{R}^{2}$ & $\Delta F$ & $F$ & $d f$ \\
\hline \multirow{3}{*}{$\begin{array}{l}\text { SD Following } \\
\text { Distance } \\
\text { Highway }\end{array}$} & Forced & Age Group & .289 & .281 & .289 & $33.75^{*}$ & $33.75^{*}$ & 1,83 \\
\hline & Step-wise 1 & Comp 1 (Speed) & .324 & .308 & .035 & $4.27 *$ & $19.68 *$ & 2,82 \\
\hline & Step-wise 2 & Comp 2 (Divided) & .376 & .353 & .052 & $6.69 *$ & $16.28 *$ & 3,81 \\
\hline \multirow{2}{*}{$\begin{array}{l}\text { RMSE Lane Position } \\
\text { Highway }\end{array}$} & Forced & Age Group & .458 & .452 & .458 & $70.15^{*}$ & $70.15^{*}$ & 1,83 \\
\hline & Step-wise 1 & Comp 1 (Speed) & .489 & .477 & .031 & $5.03 *$ & $39.30 *$ & 2,82 \\
\hline \multirow{4}{*}{$\begin{array}{l}\text { SD Velocity } \\
\text { Highway } \\
\text { Time-to-complete } \\
\text { Highway }\end{array}$} & Forced & Age Group & .222 & .213 & .222 & $23.13 *$ & $23.13 *$ & 1,83 \\
\hline & Forced & Age Group & .092 & .081 & .092 & $8.38^{*}$ & $8.38^{*}$ & 1,83 \\
\hline & Step-wise 1 & Comp 2 (Divided) & .149 & .128 & .057 & $5.48^{*}$ & $7.15^{*}$ & 2,82 \\
\hline & Step-wise 2 & Comp 1 (Speed) & .189 & .159 & .040 & $3.99 *$ & $6.27 *$ & 3,81 \\
\hline \multirow{3}{*}{$\begin{array}{l}\text { SD Following } \\
\text { Distance } \\
\text { Suburban }\end{array}$} & Forced & Age Group & .247 & .237 & .247 & $24.83^{*}$ & $24.83^{*}$ & 1,76 \\
\hline & Step-wise 1 & Comp 1 (Speed) & .356 & .339 & .109 & $12.73 *$ & $20.73 *$ & 2,75 \\
\hline & Step-wise 2 & Comp 4 (Executive) & .392 & .367 & .036 & $4.39 *$ & $15.91 *$ & 3,74 \\
\hline $\begin{array}{l}\text { RMSE Lane Position } \\
\text { Suburban }\end{array}$ & Forced & Age Group & .098 & .086 & .098 & $8.25^{*}$ & $8.25^{*}$ & 1,76 \\
\hline $\begin{array}{l}\text { SD Velocity } \\
\text { Suburban } \\
\end{array}$ & Forced & Age Group & .289 & .281 & .289 & $33.75^{*}$ & $33.75^{*}$ & 1,83 \\
\hline \multirow[t]{2}{*}{$\begin{array}{l}\text { Time-to-complete } \\
\text { Suburban }\end{array}$} & Forced & Age Group & .001 & -.012 & .001 & 0.07 & 0.07 & 1,76 \\
\hline & Step-wise 1 & Comp 1 (Speed) & .106 & .08 & .105 & $8.81^{*}$ & $4.45^{*}$ & 2,75 \\
\hline \multirow{4}{*}{$\begin{array}{l}\text { SD Following } \\
\text { Distance } \\
\text { Merge Off-ramp }\end{array}$} & Forced & Age Group & .279 & .270 & .279 & $31.29 *$ & $31.29 *$ & 1,81 \\
\hline & Step-wise 1 & Comp 1 (Speed) & .324 & .307 & .046 & $5.39 *$ & $19.19^{*}$ & 2,80 \\
\hline & Step-wise 2 & Comp 2 (Divided) & .367 & .343 & .043 & $5.30^{*}$ & $15.25^{*}$ & 3,79 \\
\hline & Step-wise 3 & Comp 5 (Selec/Inhib) & .402 & .372 & .036 & $4.63 *$ & $13.12 *$ & 3,78 \\
\hline $\begin{array}{l}\text { RMSE Lane Position } \\
\text { Merge Off-ramp }\end{array}$ & Forced & Age Group & .160 & .150 & .160 & $15.29 *$ & $15.29 *$ & 1,80 \\
\hline $\begin{array}{l}\text { SD Velocity } \\
\text { Merge Off-ramp }\end{array}$ & Forced & Age Group & .233 & .224 & .233 & $24.24 *$ & $24.34 *$ & 1,80 \\
\hline
\end{tabular}

As can be seen in Table 3, age group accounted for significant variance for most of the measures of simulated driving performance, where younger drivers had shorter following distance from the lead vehicle, less lateral deviations from lane center, faster mean velocity, and shorter time to complete than older drivers. Further, for many of the measures the attention components explained significant variance in driving performance beyond age group. Component 1 , the speed component, was significant for most performance measures that differed between groups. Component 2 , the divided component, explained additional variance beyond age group and the speed component for the SD lead-vehicle following distance in two of the three events examined. In the suburban segment, Component 4, the executive component, was significant. Finally, the most complex behavior we examined, the merge to the off-ramp, had the most complex model where age group, Component 1 (speed), 2 (divided), and 5 (selective/inhibition) all explained significant variance. 


\section{DISCUSSION}

The current study expanded our previous research on using attention components to predict simulated driving (Nelson, Tuttle, \& Backs, 2007) to the senior driver age group. The attention components obtained in the current study generally support the component structure obtained in Nelson et al. with younger adults. Further, when examined separately, the component structure for the younger and older groups were similar enough to each other to warrant the use of a single component solution for all participants. The current study also used a more naturalistic driving scenario than did Nelson et al. because specific driving events were simulated that were identified in the Canadian Consensus Report (Korner-Bitensky et al., 2005) as being particularly important to assess in older drivers.

This preliminary examination of a subset of driving behaviors suggests that individual differences the highly developed skill of driving can be predicted at least in part by individual differences in attention components. The fact that the speed and divided attention components explained variability in headway maintenance but not in lateral position is consistent with literature suggesting that headway maintenance requires focal attention and controlled processing whereas lateral position can be performed using ambient attention and is more automatic (e.g., Horrey, Wickens, \& Consalas,2006; Previc, 1998; Summala, Nieminen, \& Punto, 1996; Wickens, 2002). Other more complex driving behaviors need to be examined to see if they show the same relation. Future work will continue to develop the attention battery to better discriminate attention functions and to continue to increase the external validity of the simulated driving scenario using a more realistic simulator. It is also imperative to external validity to decrease the loss of older participants because of motion discomfort, so the development of counter-measures (e.g., Wesley, Sayer, \& Tengler, 2005) will be very important in future studies.

\section{ACKNOWLEDGEMENT}

This research was supported by a CMU Student Research and Creative Endeavors award to the first author.

\section{REFERENCES}

Ball, K. (1997). Enhancing mobility in the elderly: Attentional interventions for driving. Assessment and Intervention Issues Across the Life Span, 267-292.

Barkley, R.A., Murphy, K.R., DuPaul, G.J. \& Bush, T. (2002). Driving in young adults with attention deficit hyperactivity disorder: Knowledge, performance, adverse outcomes, and the role of executive functioning. Journal of the International Neuropsychological Society, 98, 1089-1095.

Eby, D., Molnar, L., \& Kartje, P. (2009). Maintaining Safe Mobility in an Aging Society. Boca Raton, FL: CRC Press.

Eby, D., Molnar, L., \& Shope, J. (2000). Driving Decisions Workbook. Michigan University, Ann Arbor, Transportation Research Institute, Social and Behavioral Analysis Division. 
Fan, J., McCandliss, B.D., Sommer, R., Raz, A., \& Posner, M.I. (2002). Testing the efficiency and independence of attentional networks. Journal of Cognitive Neuroscience, 14(3), 340347.

Folstein, M. F., Folstein, S. E. \& McHugh, P. R. (1975). Mini Mental State: A practical method for grading the cognitive state of patients for the clinician. Journal of Psychiatric Research, $12,189-198$.

Hallett, P.E. (1978). Primary and secondary saccades to goals defined by instructions. Vision Research, 18(10), 1279-1296.

Heaton, R. K. (1981). Wisconsin Card Sort Test. Manual: revised and expanded. Odessa, TX: Psychological Assessment Resources.

Horrey, W.J., Wickens, C.D., \& Consalus, K.P. (2006). Modeling drivers visual attention allocation while interacting with in-vehicle technologies. Journal of Experimental Psychology: Applied, 12, 67-78.

Korner-Bitensky N, Gelinas I, Man-Son-Hing M, \& Marshall S. (2005). Recommendations of the Canadian Consensus Conference on driving evaluation in older drivers. In W. Mann (Ed.), Community Mobility: Driving and Transportation Alternatives for Older Persons, 585605. New York: Haworth Press.

Land, T. L., Secretary of State. (2006). What every driver must know. State of Michigan. Retrieved April 6, 2007 from the Department of State of Michigan Website: http://www.michigan.gov/sos/0,1607,7-127-1642-103522--,00.html

Neisser, U. (1963). Decision time without reaction time. American Journal of Neuroscience, 14(3), 340-347.

Nelson, M., Tuttle, S., \& Backs, R. W. (2007). An examination of the relationship between attention profiles and simulated driving performance. Proceedings of the Fourth International Driving Symposium on Human Factors in Driver Assessment, Training, and Vehicle Design (pp. 423-430). Iowa City, IA: University of Iowa.

Posner, M. \& Peterson, S. (1990). The attention system of the human brain. Annual Review of Neuroscience 13, 25-42

Previc, F.H. (1998). The neuropsychology of 3-D space. Psychological Bulletin, 124, 123-164.

Reitan, R.M. (1958). Validity of trail making test as an indicator of organic brain damage. Perceptual and Motor Skills, 8, 271-276.

Stroop, J.R. (1935). Studies of interference in serial verbal reactions, Journal of Experimental Psychology, 12, 643-662.

Summala, H., Nieminen, T., \& Punto, M. (1996). Maintaining lane position with peripheral vision during in-vehicle tasks. Human Factors, 38, 442-451.

U.S. Department of Transportation (2005). NHTSA Traffic Safety Facts 2005: A Compilation of Motor Vehicle Crash Data from the Fatality Analysis Reporting System and the General Estimates System. Report DOT HS 810 631, National Center for Statistics and Analysis, National Highway Safety Administration. Washington, DC. 
Washburn, D \& Putney, R.T. (1997). Assessment software for attention profiles.

Wesley, A.D., Sayer, T.B., \& Tengler, S. (2005). Can Sea Bands be used to mitigate simulator sickness? Proceedings of the Third International Driving Symposium on Human Factors in Driver Assessment, Training, and Vehicle Design (pp. 297-393). Iowa City, IA: University of Iowa.

Wickens, C.D. (2002). Multiple resources and performance prediction. Theoretical Issues in Ergonomics Sciences, 3, 159-177. 